\title{
Frequency of impacted teeth and categorization of impacted canines: A retrospective radiographic study using orthopantomograms
}

\author{
Hassan Al-Zoubi ${ }^{1}$, Abdulgader Abdullatif Alharbi ${ }^{2}$, Donald J. Ferguson ${ }^{3}$, \\ Muhammad Sohail Zafar ${ }^{4,5}$
}

Correspondence: Dr. Muhammad Sohail Zafar

'Department of Pediatric Dentistry and Orthodontics, College of Dentistry, Taibah University, Al Madinah, Al Munawwarah 41311, Saudi Arabia,

${ }^{2}$ Specialty Dental Center, King Fahad Hospital, Al Madinah, Al Munawwarah 41311, Saudi Arabia, ${ }^{3}$ Department of Orthodontics, European University College, Dubai 53382, UAE,

${ }^{4}$ Department of Restorative Dentistry, College of Dentistry, Taibah University, Al Madinah, Al Munawwarah, Saudi Arabia,

Correspondence: Dr. Muhammad ${ }^{5}$ Visiting Professor, Department of Dental Materials, Islamic International Dental College, Riphah International University, Islamabad 44000, Pakistan

\section{ABSTRACT}

Objective: The objective of this study is to determine the frequency of impacted maxillary canines using seven subtype classification system. For this purpose, impacted maxillary canines have been divided into seven various subtypes. Materials and Methods: This is a descriptive, cross-sectional, and retrospective study conducted using radiographic data of residents of Madinah, Al Munawwarah. Radiographic data of 14,000 patients, who attended College of Dentistry, Taibah University, from January 2011 to February 2015, were screened against the selection criteria for the presence of impacted teeth. The individuals with maxillary impacted canines were matched to maxillary canine impaction. The occurrence of each subtype of impacted canines was calculated. Results: Impacted teeth are more common in the maxilla compared to mandible. The impacted canine represented the highest proportion of all impacted maxillary teeth followed by the second premolars and the central incisors. According to the classification system represented, Type II of canine impaction comprised the highest proportion $(51 \%)$ while Type IV $(0.5 \%)$ comprised the lowest frequency. The maxillary canine is the most frequently impacted tooth followed by mandibular canines. Conclusions: Although there are many variations, the majority of impacted canines fall into Type II of the classification of impacted canines.

Key words: Canine, impaction, maxillary teeth, orthodontics

\section{INTRODUCTION}

Impacted teeth are defined as teeth that remain completely or incompletely embedded in the

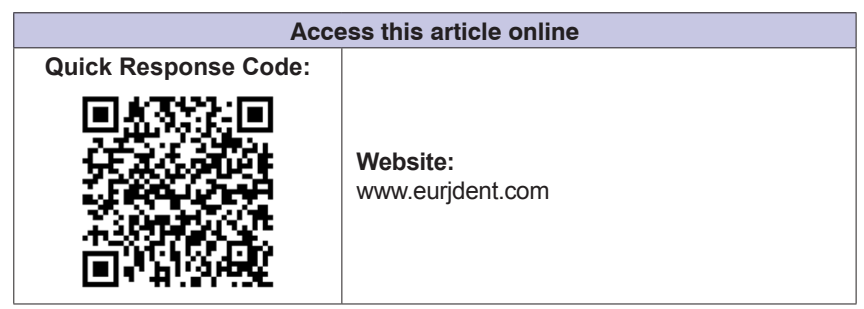

jawbone or mucosa for more than 2 years following physiological eruption time. ${ }^{[1]}$

This is an open access article distributed under the terms of the Creative Commons Attribution-NonCommercial-ShareAlike 3.0 License, which allows others to remix, tweak, and build upon the work non-commercially, as long as the author is credited and the new creations are licensed under the identical terms.

For reprints contact: reprints@medknow.com

How to cite this article: Al-Zoubi H, Alharbi AA, Ferguson DJ, Zafar MS. Frequency of impacted teeth and categorization of impacted canines: A retrospective radiographic study using orthopantomograms. Eur J Dent 2017; 11:117-21.

DOI: 10.4103/ejd.ejd_308_16 
Although there are wide variations in impacted teeth among individuals, third molars remain the most prevalent impacted teeth followed by maxillary canines. ${ }^{[2]}$ Multiple factors are considered responsible for higher impaction prevalence of canines; for instance, maxillary canines have comparatively longer roots and path of eruption, develop deep into the jaw, and erupt following neighboring teeth. In contrast, mandibular canine impactions are significantly less frequent compared to maxillary canines. ${ }^{[3]}$ In addition, genetic factors play a significant role in the development of maxillary canine impactions (MCIs). ${ }^{[4]}$

The potential of the maxillary canine for impactions and eruption guidance facilitated by lateral incisor are controlled by genetics. Therefore, the developmental stage of a tooth has a key role in guiding the ultimate position of canines and malocclusions. ${ }^{[5]}$ Although unilateral ectopic eruptions of canine are not very uncommon, the bilateral occurrence of maxillary canines is usual. ${ }^{[6]}$

In terms of timely diagnosis, it is often difficult to determine whether the missing canine is truly impacted or delayed eruption, especially in young patients. Hence, the detailed assessment of impact tooth for its location, angulation, and orientation is important for orthodontic treatment planning. For this purpose, a variety of radiographic assessment tools have been used to evaluate the impacted canines. Although cone-beam computed tomography has benefits of evaluating tissue dimensions more precisely and has been used for applications in general dentistry ${ }^{[7-9]}$ as well as orthodontics, ${ }^{[10]}$ high radiation dose is the major concern. In comparison, the panoramic radiograph (orthopantomogram [OPG]) uses remarkably lower radiation dose and provides comprehensive information regarding whole dentition, jaws, and the surrounding structures, which is frequently used for initial assessment. ${ }^{[7]}$

The criteria to classify the maxillary canines have been described previously that showed a promising harmony with the clinician's perception for orthodontic treatment planning. ${ }^{[11]}$ In the current study, we used a classification system for impacted maxillary canines according to their long-axis angles and the occlusal plane. The major aim of the current study is to establish the frequency of impacted maxillary canines according to the classification system. For this purpose, impacted maxillary canine has been categorized into seven subtypes.

\section{MATERIALS AND METHODS}

This is a descriptive, cross-sectional, and retrospective study conducted using radiographic data of dental patients attending College of Dentistry, Taibah University, Madinah, Al Munawwarah. The study protocol was approved by Taibah University, College of Dentistry Research Ethics Committee. The OPGs are routinely used for screening and pretreatment diagnostic imaging. Data of 14,000 patients' (age range: $14-70$ years) OPG images (7000 males, 7000 females), attending College of Dentistry, Taibah University, from January 2011 to February 2015, were included in this study. The inclusion and exclusion criteria have been mentioned in Table 1. All the included OPG images were screened for the presence of impacted teeth. This investigation included at least one or more impacted permanent canines that are not likely to erupt in the future such as those causing resorption in the root of the lateral incisor, inverted canines, and displaced canines.

The classification system reported by Yamamoto et al. ${ }^{[12]}$ presented all conceivable positions of MCI according to their long-axis angles and the occlusal plane [Figure 1]. The individuals with maxillary impacted canines $(n=351)$ fulfilling the selection criteria (167 in male and 184 in female patients) were matched to seven subtypes of this classification system of MCI. The data collected were descriptively analyzed to establish the frequency of various types of impacted canines. The

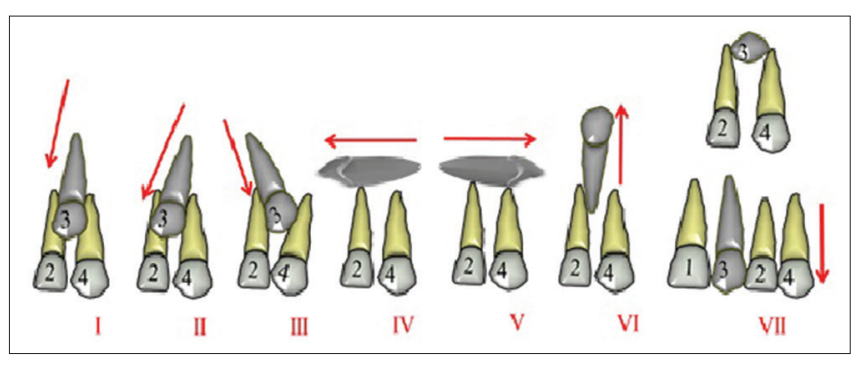

Figure 1: Schematic representation of the classification system of maxillary canine impaction used in this study: seven different types have been used based on anatomical relationship of impacted canines. Tooth 3 represents maxillary canine; teeth 2 and 4 represent maxillary lateral incisor and first premolar, respectively

Table 1: Selection criteria used to filter retrospective
orthopantomography of patients


data were statistically analyzed using SPSS software version 20 (IBM, Portsmouth, Hampshire, UK).

\section{RESULTS}

\section{Frequency of impacted teeth with tooth position}

The frequency of impacted teeth varied depending on tooth number. A total of 354 individuals (181 males, 173 females) reported impacted teeth $(n=479)$ excluding third molars [Table 2]. There was no significant difference in the number of male $(51.1 \%)$ and female $(48.9 \%)$ patients with impacted teeth $(P=0.059)$. Impacted teeth occurred more often in the maxilla (79.3\%) compared to the mandible (20.7\%).

Among maxillary impacted teeth $(n=380)$, the most frequently impacted teeth remain maxillary canines (third molars excluded) that contributed $92.4 \%$ of maxillary impacted teeth and $73.2 \%$ of all impacted teeth. The number of impacted central incisors, first and second premolars in maxilla was 8 (2.1\%), 6 (1.6\%), and $15(3.8 \%)$, respectively. Although the number of teeth impacted in the right maxilla was greater than that of left maxilla, there was no specific relation of statistical significance for any tooth [Table 2]. There was no incidence of impacted lateral incisors in the maxilla and the first and second molars in maxilla as well as in mandible. In mandibular arch, canine was the most frequently impacted tooth $(49.5 \%)$ followed by the second premolars (37.4\%) and the first premolars (11.1\%). Impacted central $(1 \%)$ and lateral $(1 \%)$ incisors were observed in one patient. The current study reported a higher prevalence of impacted maxillary canines on the left side $(n=205)$ compared to the right side $(n=146)$.

Occurrence of maxillary canine impactions and types The impacted maxillary canine teeth $(n=351)$ were classified according to gender, tooth direction and position. The female patients showed higher proportion

\begin{tabular}{|c|c|c|c|c|c|c|}
\hline & \multicolumn{3}{|c|}{ Maxilla } & \multicolumn{3}{|c|}{ Mandible } \\
\hline & Right & Left & Total (\%) & Right & Left & Total (\%) \\
\hline Central incisor & 8 & 0 & $8(2.1)$ & 1 & 0 & $1(1.0)$ \\
\hline Lateral incisor & 0 & 0 & 0 & 0 & 1 & $1(1.0)$ \\
\hline Canine & 146 & 205 & $351(92.4)$ & 20 & 29 & $49(49.5)$ \\
\hline First premolar & 1 & 5 & $6(1.6)$ & 6 & 5 & $11(11.1)$ \\
\hline $\begin{array}{l}\text { Second } \\
\text { premolar }\end{array}$ & 4 & 11 & $15(3.8)$ & 17 & 20 & $37(37.4)$ \\
\hline First molar & 0 & 0 & 0 & 0 & 0 & 0 \\
\hline Second molar & 0 & 0 & 0 & 0 & 0 & 0 \\
\hline Total & 159 & 221 & $380(100)$ & 44 & 55 & $99(100)$ \\
\hline
\end{tabular}

of impacted maxillary canine (184/351) compared to male patients $(167 / 351)$. Figure 2 represents the description of types of impacted canines and their representative OPG images. The highest proportion of impacted maxillary canines matched to Type II (51.6\%) followed by Type IV (28.2\%), Type I (12.5\%), and Type III (4.8\%). Type VII impacted canines were $2.3 \%$ and Type VI were only $0.6 \%$. There was no case of Type $\mathrm{V}$ in the chosen population [Table 3]. The frequency of Type II MCI was significantly higher compared to any other type $(P=0.053)$.

\section{DISCUSSION}

The current study has reported the frequency of impacted permanent teeth excluding third molars. The permanent teeth impaction is commonly observed that may involve any tooth. The incidence of tooth impaction varies among various ethnic populations

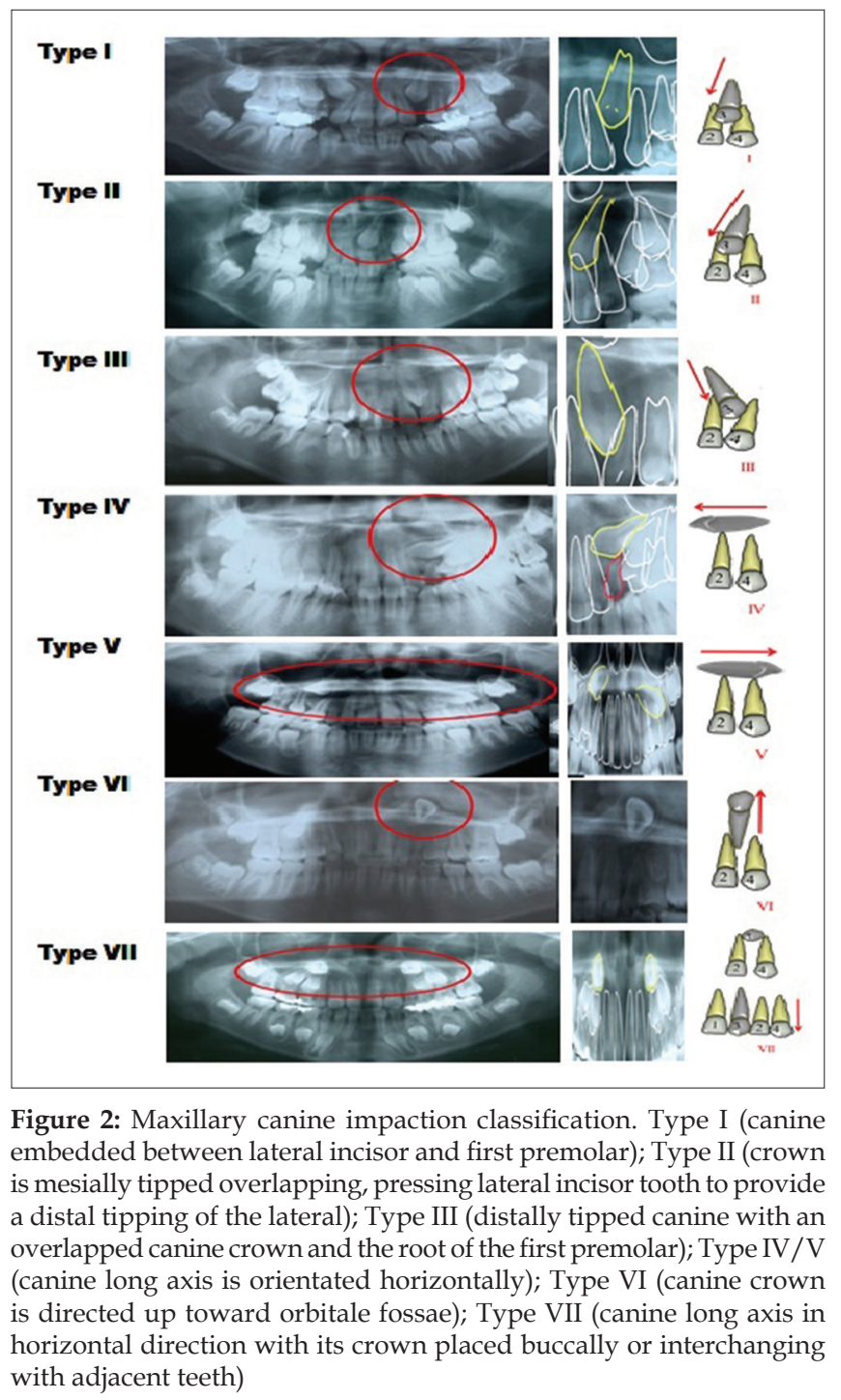




\begin{tabular}{lc}
\multicolumn{2}{l}{ Table 3: Occurrence of various types of impacted } \\
canines classified using proposed classification \\
\hline Canine impaction type & Frequency (\%) \\
\hline I & $44(12.5)$ \\
II & $181(51.6)$ \\
III & $17(4.8)$ \\
IV & $99(28.2)$ \\
V & 0 \\
VI & $2(0.6)$ \\
VII & $8(2.3)$ \\
Total & $351(100)$ \\
\hline
\end{tabular}

from $5.6 \%$ to $18.8 \% \cdot{ }^{[13-15]}$ For instance, the prevalence of impacted maxillary canines has been reported as $5.4 \%$ among Hungarian, ${ }^{[16]} 5.1 \%$ among Turkish, ${ }^{[17]}$ and $2.1 \%$ among Chinese ${ }^{[18]}$ orthodontic patients. A new classification has been proposed to classify the most frequently impacted maxillary canines. The upper canines are only second to the upper and lower third molars in frequency of impaction. ${ }^{[19]}$

There are multiple factors involved in higher frequency of MCIs with a wide range of variations that require their classification. For instance, the higher frequency may primarily be caused by the lack of eruption space as canines erupt later than the adjacent teeth. In addition, the maxillary canine tooth germ develops at 24 weeks of gestation and remains embedded in the maxilla for approximately 12 years. The tooth erupts later than any other permanent tooth at the age of 11-12 years. Delayed eruption leads to certain physiological changes including increased bone density and pressure from surrounding anatomical structures such as the nasal cavity, orbital cavity, and maxillary sinus. ${ }^{[19]}$

In contrast, the upper lateral incisor germ starts developing around 5-5.5 months of gestation and erupts at the age of 8-9 years, which is also earlier than the upper canine. The germ of the first premolar develops at birth (later than upper canine) and eruption occurs at the age of 10-11 years. Therefore, a space needs to be maintained between the erupted lateral incisor and the first premolar to facilitate canine eruption in the normal position. ${ }^{[20]}$ In addition to delayed eruption, the deep positioning of the canine germ also contributes to their impaction. Teeth that move only a short distance before eruption are less likely to be impacted. For example, in the case of the first molar, tooth germ is formed closest to the occlusal plane and rarely impacted. ${ }^{[20]}$ Conversely, the canine tooth germ is formed deep into the maxilla and hence its eruption can be affected by lateral incisor and long path of eruption. The upper canine normally runs along the root of the lateral incisor with the forming crown slightly inclined mesially at the distolabial side of the root of the incisor. ${ }^{[21]}$ Majority of impacted canines are likely to cause root resorption of lateral incisors. ${ }^{[22]}$

This indicates the importance of the lateral incisor in canine tooth eruption, given that the canine erupts along the root of the lateral incisor while inclined. In addition, canine replaces a deciduous tooth that is narrower and has to break through the hard palate and palatal mucosa. ${ }^{[23]}$ The current study reported 167 impacted canines in male and 184 in female patients, suggesting that canine impaction is more common among females. These findings are in agreement with a previous study by Hou et al. ${ }^{[24]}$ The gender differences may be attributable to the fact that the sizes of skull, maxilla, and mandible are smaller in women than in men. ${ }^{[20]}$

An appropriate jaw size is an important parameter required to facilitate the growth and eruption of teeth in order. Discrepancies in jaw size corresponding to evolutionary changes and lack of sagittal growth are likely to enhance the probability of tooth impactions. ${ }^{[25]}$ Similarly, arch length deficiency is known to cause impaction of teeth. For instance, a dysplastic premaxilla can alter the path of eruption of maxillary canine following the eruption of lateral incisor hence increasing the chances of its impaction. ${ }^{[26]}$ In cleft and palate patients having deficit skeletal growth of maxilla, the frequency of $\mathrm{MCI}$ has been reported significantly higher compared to controls. ${ }^{[27]}$

The current study reported that more than $92 \%$ of the maxillary impacted teeth were canines ( 73\% of all the impacted teeth). Brin et al. ${ }^{[28]}$ reported similar occurrence of the impacted maxillary canine and third molar. Incidence of impacted maxillary canine ranged from $0.92 \%$ to $3.58 \%$ in the general population. A number of studies have reported that the majority $(85 \%)$ of the impacted maxillary canines are palatal ${ }^{[13,29]}$ compared to the labial $(15 \%)$. On the other hand, the bilateral occurrence of $\mathrm{MCI}$ is also a common occurrence; however, unilateral ectopic eruptions are more frequent. ${ }^{[14]}$ Although the mandibular canine impaction is more frequent compared to incisors and premolars, it is significantly less common compared to impacted maxillary canines. Yavuz et al. ${ }^{[30]}$ described a greater frequency of impacted mandibular canines $(1.29 \%)$ in the Turkish population.

The current study reported a higher prevalence of impacted maxillary canines on the left side $(n=205)$ compared to the right side $(n=146)$. These findings are 
in agreement with a previous study by Takahama and Aiyama ${ }^{[27]}$ that reported a higher frequency of left-sided maxillary impactions in cleft patients $(66.7 \%)$ as well as in the control group (62.5\%). Although there are no scientific evidences to explain the higher prevalence of left-sided MCIs, it has been considered as a general trait of malformation. ${ }^{[27]}$ The canines play a vital role during orthodontic treatment planning and occlusal stability. Hence, impacted canines require a particular attention. In this study, the occurrence of impacted maxillary canines was recorded in terms of variation in the long axis and depending on eruption feature of maxillary canine rather than on simply labial or palatal positions. The current study demonstrated that the percentage of impaction was similar for the canine which showed higher percentages of impaction than the second premolar (about $49 \%$ and $37 \%$, respectively) in the lower dentition. In contrast, Bishara ${ }^{[31]}$ and Orton et al. ${ }^{[32]}$ reported the mandibular second premolar as one of the most commonly impacted teeth followed by lower second premolars $(\sim 24 \%)$. The prevalence of maxillary second premolar impaction $(9.85 \%)$ was less than that of the mandibular second premolar.

\section{CONCLUSIONS}

Excluding the third molars, maxillary canine is the most commonly impacted tooth followed by mandibular canines. The classification system with seven subtypes is a useful tool for categorizing impacted maxillary canines and treatment planning. The majority of impacted maxillary canines (51\%) had mesially tipped crown and pressing and distally tipping the lateral incisors (Type II). Among impacted canines, the horizontal orientation of the canine long axis (Type IV and V) was rare. Considering the complexities, the impacted canines may present in a wide range of variations in their long axis and must be assessed carefully during treatment planning.

\section{Financial support and sponsorship}

Nil.

\section{Conflicts of interest}

There are no conflicts of interest.

\section{REFERENCES}

1. Bass TB. Observations on the misplaced upper canine tooth. Dent Pract Dent Rec 1967:18:25-33.

2. Pedro FL, Bandéca MC, Volpato LE, Marques AT, Borba AM, Musis CR, et al. Prevalence of impacted teeth in a Brazilian subpopulation. J Contemp Dent Pract 2014;15:209-13.

3. Röhrer A. Displaced and impacted canines A radiographic research. Int J Orthod Oral Surg Radiogr 1929;15:1003-20.

4. Chung DD, Weisberg M, Pagala M. Incidence and effects of genetic factors on canine impaction in an isolated Jewish population. Am J Orthod Dentofacial Orthop 2011;139:e331-5.

5. Sajnani AK, King NM. The sequential hypothesis of impaction of maxillary canine - A hypothesis based on clinical and radiographic findings. J Craniomaxillofac Surg 2012;40:e375-85.

6. Richardson G, Russell KA. A review of impacted permanent maxillary cuspids - Diagnosis and prevention. J Can Dent Assoc 2000;66:497-501.

7. Jung YH, Liang H, Benson BW, Flint DJ, Cho BH. The assessment of impacted maxillary canine position with panoramic radiography and cone beam CT. Dentomaxillofac Radiol 2012;41:356-60.

8. Zafar MS, Alrahabi M. Cone beam computed tomography for exploring morphology of mandibular first molar. Br J Med Med Res 2015;6:514-21.

9. Alrahabi M, Sohail Zafar M. Evaluation of root canal morphology of maxillary molars using cone beam computed tomography. Pak J Med Sci 2015;31:426-30.

10. Lai CS, Bornstein MM, Mock L, Heuberger BM, Dietrich T, Katsaros C. Impacted maxillary canines and root resorptions of neighbouring teeth: A radiographic analysis using cone-beam computed tomography. Eur J Orthod 2013;35:529-38.

11. Kau CH, Lee JJ, Souccar NM. The validation of a novel index assessing canine impactions. Eur J Dent 2013;7:399-404.

12. Yamamoto G, Ohta $Y$, Tsuda $Y$, Tanaka A, Nishikawa M, Inoda H. A new classification of impacted canines and second premolars using orthopantomography. Asian J Oral Maxillofac Surg 2003;15:31-7.

13. Shah RM, Boyd MA, Vakil TF. Studies of permanent tooth anomalies in 7,886 Canadian individuals. II: Congenitally missing, supernumerary and peg teeth. Dent J 1978;44:265-8, 276.

14. Thilander B, Myrberg N. The prevalence of malocclusion in Swedish schoolchildren. Eur J Oral Sci 1973;81:12-20.

15. Delli K, Livas C, Bornstein MM. Lateral incisor agenesis, canine impaction and characteristics of supernumerary teeth in a South European male population. Eur J Dent 2013;7:278-83.

16. Rózsa N, Fábián G, Szádeczky B, Kaán M, Gábris K, Tarján I. Prevalence of impacted permanent upper canine and its treatment in 11-18-year-old orthodontic patients. Fogorv Sz 2003;96:65-9.

17. Celikoglu M, Kamak H, Oktay H. Investigation of transmigrated and impacted maxillary and mandibular canine teeth in an orthodontic patient population. J Oral Maxillofac Surg 2010;68:1001-6.

18. Zhong YL, Zeng XL, Jia QL, Zhang WL, Chen L. Clinical investigation of impacted maxillary canine. Zhonghua Kou Qiang Yi Xue Za Zhi 2006;41:483-5.

19. Andreasen JO, Peterson J, Laskin DM. Textbook and color atlas of tooth impactions. Am J Orthod Dentofacial Orthop 1997;112:354.

20. Archer WH. Oral and Maxillofacial Surgery. Philadelphia, USA: WB Saunders Company; 1975.

21. Ericson S, Kurol J. Incisor resorption caused by maxillary cuspids. A radiographic study. Angle Orthod 1987;57:332-46.

22. Becker A, Zilberman Y, Tsur B. Root length of lateral incisors adjacent to palatally-displaced maxillary cuspids. Angle Orthod 1984;54:218-25.

23. Ericson S, Kurol J. Radiographic assessment of maxillary canine eruption in children with clinical signs of eruption disturbance. Eur J Orthod 1986;8:133-40.

24. Hou R, Kong L, Ao J, Liu G, Zhou H, Qin R, et al. Investigation of impacted permanent teeth except the third molar in Chinese patients through an X-ray study. J Oral Maxillofac Surg 2010;68:762-7.

25. Quek SL, Tay CK, Tay KH, Toh SL, Lim KC. Pattern of third molar impaction in a Singapore Chinese population: A retrospective radiographic survey. Int J Oral Maxillofac Surg 2003;32:548-52.

26. Jacoby H. The etiology of maxillary canine impactions. Am J Orthod 1983;84:125-32

27. Takahama Y, Aiyama Y. Maxillary canine impaction as a possible microform of cleft lip and palate. Eur J Orthod 1982;4:275-7.

28. Brin I, Becker A, Shalhav M. Position of the maxillary permanent canine in relation to anomalous or missing lateral incisors: A population study. Eur J Orthod 1986;8:12-6.

29. Grover PS, Lorton L. The incidence of unerupted permanent teeth and related clinical cases. Oral Surg Oral Med Oral Pathol 1985;59:420-5.

30. Yavuz MS, Aras MH, Büyükkurt MC, Tozoglu S. Impacted mandibular canines. J Contemp Dent Pract 2007;8:78-85.

31. Bishara SE. Impacted maxillary canines: A review. Am J Orthod Dentofacial Orthop 1992;101:159-71.

32. Orton HS, Garvey MT, Pearson MH. Extrusion of the ectopic maxillary canine using a lower removable appliance. Am J Orthod Dentofacial Orthop 1995;107:349-59. 